Pak. J. Agri., Agril. Engg., Vet. Sci., 2020, 36 (1): 42-54

ISSN: 1023-1072 (Print), ISSN: 2663-7863 (Online)

https://doi.org/10.47432/pjaaevs.2020.36.1.7

\title{
REVIVING NIGERIAN RUBBER INDUSTRY
}

\author{
M. S. Sadiq ${ }^{1}$, I. P. Singh ${ }^{2}$ and M. M. Ahmad ${ }^{3}$ \\ ${ }^{1}$ Department of Agricultural Economics and Extension, FUD, Dutse, Nigeria \\ ${ }^{2}$ Department of Agricultural Economics, SKRAU, Bikaner, India \\ ${ }^{3}$ Department of Agricultural Economics, BUK, Kano, Nigeria
}

\begin{abstract}
The present research empirically looks at the possibility of devising a mechanism of reviving Nigerian rubber industry. The research used dated data that spanned from 1961 to 2017 and it covered production, area, yield and producer's price (rubber). The data were drawn from the FAO database and analyzed using both descriptive and inferential statistics. Empirical evidence showed that the incremental change in the country's rubber production was majorly driven by area effect which necessitates area risk owing to pressure on the limited available land for other purposes to be the main factor that affected the average output of rubber in the country. Furthermore, the future of the subsector is not promising owing to the fact that the slight gentle rise in the forecasted production trend will be driven by a gentle incremental rise in annual area as the annual yield level year-in-year-out plummeted. The decrease in the forecasted annual yield levels will be as a result of non-productive income and not technology, because farmers are at the mercy of the Licensed Buyers (LBs) who exploit them given that they used collusive effect other than allow the market forces to determine the prevailing market price as they serve as the major link to the importing markets. Therefore, the study recommends that the farmers should constitute themselves into viable co-operative organizations in order to venture into export marketing so that they can take advantage of their bargaining power.
\end{abstract}

Keywords: Nigeria, production, revival, rubber

\section{INTRODUCTION}

Little or nothing of foreign exchange earnings from the three major cash crops is being heard today, viz. palm oil, groundnuts and rubber, a leading export goods of Nigeria. Although rubber plantation is one of Nigeria's well-growing resources, successive governments' policy inconsistency had neglected this sub-sector, which was once the fourth largest foreign earning source after crude oil. This industry has been made unattractive by the mono-economysole dependence on crude oil. In addition, the research institutes mandated to develop improved seed varieties have also gone comatose and even most of the existing plantations are old as they were established in 1960s (Agbota, 2017). Besides, the dearth of modern equipment necessary for value addition of international standard has been attributed to be responsible for the decline in rubber production as argued by the stakeholders.

Because the old plantation has not been replenished and new ones not established,

*Corresponding author: sadiqsanusi30@gmail.com
Agbota (2017) reported that experts were of the opinion that the capacity of the rubber industry in the country had plummeted from well above 130 MT per year to between 55,000 and 60,000 MT. The export capacity declined from around 100,000 MT per year to between 60 and 80 MT, representing about 20 percent. The rate at which the automotive industry mops up natural rubber worldwide explains how invaluable it is in human activities. Thus, given the above submissions, farming needs to be given desirable attention because a time comes when oil will not be able to sustain the recent economy-advanced countries are moving from hydrocarbon-ecofriendly to green energy-eco-friendly countries. Nigeria's exit of global giants Michelin and Dunlop was the highpoint of the rubber industry's decline. The industry which created over 54 businesses at its peak now has fewer than 20 businesses (Ambrose, 2018).

The neglect of the sub-sector by the government which is evident by the almost extinction of this cash crop despite being one of the plant products mostly used in virtually any industry has caused the country colossal annual 
revenue loss of approximately $\$ 6$ billion in the international market. Rubber is regarded as a money-spinner in some countries due to its high demand for various purposes ranging from engineering, aviation, education, sports, health etc. The rate at which the automotive industry mops up natural rubber worldwide explains how invaluable it is in human activities. Thus, in view of the above submissions, agriculture needs to be given desirable attention because a time will come when oil can not sustain the economy. Of recent, developed countries are shifting from hydrocarbon-eco-unfriendly to green energyeco-friendly. The implication is, we shouldn't expect an oil price hike; the price will continue to dampen. It is therefore very imperative for the country to embark on large-scale cash crop cultivation, so that when the oil fails, cash crop exports will not fail the economy.

The need to shore-up the continuous widening gap of the nation's revenue owing to dwindling oil price has forced the Nigerian government to start looking towards non-oil products especially agricultural cash crops for foreign exchange earnings. Since agriculture was the mainstay of the Nigerian economy before the oil boom, the need to look into this sub-sector to keep the nation's economy afloat becomes a sine-qua-non. Thus, it is on this thrust that the present research was conceptualized with the aim of charting a pathway for the revival of the sub-sector with the view to explore the economic prospect of rubber commodity for national development. Revitalization of the neglected sector has the potential to drive ongoing economic diversification for the Federal Government, job creation for the various stakeholders along the value chain and the potential to spur industrialization. The specific objectives were to determine the trend and growth patterns of rubber production; determine the extent and sources of instability in rubber production; determine the sources of change in the average production; determine the factors influencing farmers' acreage response; and, to forecast the future production trend of rubber in the studied area.

\section{MATERIALS AND METHODS}

Nigeria is situated between latitudes 4' to 14 ' $\mathrm{N}$ and 2' to 15 ' $\mathrm{E}$ of the Greenwich meridian time (CIA, 2011) and has a vast area of land suitable for various agricultural purposes viz. livestock, fisheries, crop production etc due to suitable prevailing agro-climatic conditions. The country has abundant untapped potential human and environmental resources. The study utilized data from time series which ranged for 56 years (1961-2017) and it covered production, area, yield and producer's price (rubber). The source of the data is the FAO database and the data collected were analysed using both descriptive and inferential statistics. The trend and growth pattern were determined using descriptive statistics and the growth model while the extent and source of instability in the production were determined using instability indexes viz. coefficient of variation (CV), Cuddy-Della Valle index, Coppock's index and Hazell's variance decomposition model. Changes in average production and farmers' acreage response were determined by Instantaneous change model and Hazell's average decomposition model; and the Nerlove's Adjustment model, while the ARIMA model was used to predict the future trens in production.

\section{Empirical model \\ Growth rate}

Calculated using the exponential model, the compound annual growth rate is given below:

$$
\begin{aligned}
& \gamma=\alpha \beta^{t} \\
& \ln \gamma=\ln \alpha+\operatorname{tn} \beta \\
& C A G R=[\text { Antilog } \beta-1] \times 100
\end{aligned}
$$

Where, CAGR is compound rate of growth; $t$ is time period in year; $\gamma$ is area/yield/production; $\alpha$ is intercept; and, $\beta$ is the estimated coefficient of parameter.

\section{Instability index}

To measure the variability of production, area and yield of sugarcane, Coefficient of variation (CV), Cuddy-Della Valle Index and Coppock's index were used. Following Sandeep et al. (2016) and Boyal et al. (2015) the CV is shown below:

CV $(\%)=\frac{\sigma}{z} * 100$

Where,

$\sigma$ is stardard deviation and $\bar{X}$ is the mean value of area,yield or production

The simple CV overestimates the level of instability in long-term trends in time series data, while the Cuddy-Della Valle Index corrects the coefficient of variation by the index of instability as it de-trends the annual production and shows 
the exact direction of instability (Cuddy-Della Valle, 1978). Thus, capturing the instability of agricultural production and prices is a better measure, and is given below:

$C D I I=C V^{*}\left(1-R^{2}\right)^{0.5}$

Where CDII is the Cuddy-Della instability index; $\mathrm{CV}$ is the coefficient of variation; and, $\mathrm{R}^{2}$ is the coefficient of multiple determination. Following Shimla (2014) as adopted by Umar et al. (2019), the instability index was classified as low instability $(\leq 20 \%)$, moderate instability $(21-40 \%)$ and high instability (>40\%).

Unlike CV, Coppock's instability index give close approximation of the average year-to-year percentage variation adjusted for trend (Ahmed and Joshi, 2013; Kumar et al., 2017; Umar et al., 2019) and the advantage is that it measures the instability in relation to the trend in production (Kumar et al., 2017). According to Kumar et al. (2017), a higher numerical value for the index represents greater instability. Following Coppock (1962), the algebraic economic formula as used by Ahmed and Joshi (2013); Sandeep et al. (2016); Kumar et al. (2017); Umar et al. (2019) is given below:

$C I I=($ Antilog $\sqrt{\log V}-1) * 100 \ldots \ldots$

$\log V=\frac{\sum\left[\log \frac{X_{t+1}}{X_{t}}-m\right]^{2}}{N-1}$

Where,

$X_{t}=$ Area or Yield or Production in year ' $t$ ',

$N=$ number of year $(s)$,

$\mathrm{Cll}=$ Coppock's instability index;

$m=$ mean difference between the log of $X_{t+1}$ and $X_{t}$; and, $\log V=$ Logarithm Variance of the series

\section{Source of change in sugarcane production Instantaneous change}

Following Sandeep et al. (2016) the model for the instantaneous analysis of decomposition used to measure the relative contribution of area and yield to the total change in output is given below:

$P_{0}=A_{0} \times Y_{0}$
$P_{n}=A_{n} \times Y_{n}$
Where, $P, A$ and $Y$ represent the production, area and yield respectively. The subscript 0 and $n$ represent the base and the $n^{\text {th }}$ years respectively.

$P_{n}-P_{0}=\Delta P$

$A_{n}-A_{0}=\Delta A$

$Y_{n}-Y_{0}=\Delta Y$

From equation (5) and (9) we can write

$P_{0}+\Delta P=\left(A_{0}+\Delta A\right)\left(Y_{0}+\Delta Y\right)$.

Therefore,

$P=\frac{Y_{0} \Delta A}{\Delta P} \times 100+\frac{A_{0} \Delta Y}{\Delta P} \times 100+\frac{\Delta A \Delta Y}{\Delta P} \times 100$.

Production $=$ Area effect + Yield effect + Interaction effect.

Table 1. Components of change in the average production

\begin{tabular}{|l|l|l|}
\hline $\begin{array}{l}\text { Sources of } \\
\text { change }\end{array}$ & Symbols & $\begin{array}{l}\text { Components } \\
\text { of change }\end{array}$ \\
\hline $\begin{array}{l}\text { Change in mean } \\
\text { area }\end{array}$ & $\Delta \bar{A}$ & $\bar{A}_{1} \Delta \bar{Y}$ \\
\hline $\begin{array}{l}\text { Change in mean } \\
\text { yield }\end{array}$ & $\Delta \bar{Y}$ & $\bar{Y}_{1} \Delta \bar{A}$ \\
\hline Interaction effect & $\Delta \bar{A} \Delta \bar{Y}$ & $\Delta \bar{A} \Delta \bar{Y}$ \\
\hline $\begin{array}{l}\text { Changes in area- } \\
\text { yield covariance }\end{array}$ & $\Delta \operatorname{COV}(A, Y)$ & $\Delta \operatorname{COV}(A, Y)$ \\
\hline
\end{tabular}

Hazell's decomposition model

In estimating the change in average production and change in the variance of production with respect to between regimes and the overall period, Hazell's (1982) decomposition model was used. Hazell decomposed the sources of change in the average of production and change in production variance into four (4) and ten (10) components as cited by Umar et al. (2017 and 2019). Decomposition analysis of change in production assesses the quantum of increase or otherwise of production in year ' $n$ ' over the base year that results from a change in the area, productivity or interaction.

\section{Changes in average production}

It is caused by changes in the area-to-yield covariance, and changes in mean area and mean yield. The model can be seen below:

$E(P)=\bar{A} \bar{Y}+\operatorname{COV}(A, Y)$

$\Delta E(P)=E\left(P_{2}\right)-E\left(P_{1}\right)=\bar{A}_{1} \Delta \bar{Y}+\bar{Y}_{1} \Delta \bar{A}+\Delta \bar{A} \Delta \bar{Y}+\Delta \operatorname{COV}\left(A_{1} Y\right)$. 
Table 2. Components of change in variance producton

\begin{tabular}{|l|l|l|}
\hline Sources of change & Symbols & Components of change \\
\hline Change in mean area & $\Delta \bar{A}$ & $2 \bar{Y} \Delta \bar{A} C O V(A, Y)+\left\{2 \bar{A} \Delta \bar{A}+(\Delta \bar{A})^{2}\right\} V(Y)$ \\
\hline Change in mean yield & $\Delta \bar{Y}$ & $2 \bar{A} \Delta \bar{Y} C O V(A, Y)+\left\{2 \bar{Y} \Delta \bar{Y}+(\Delta \bar{Y})^{2}\right\} V(A)$ \\
\hline $\begin{array}{l}\text { Change in area } \\
\text { variance }\end{array}$ & $\Delta V(A)$ & $\bar{Y}^{2} V(A)$ \\
\hline $\begin{array}{l}\text { Change in yield } \\
\text { variance }\end{array}$ & $\Delta V(Y)$ & $\bar{A}^{2} V(Y)$ \\
\hline $\begin{array}{l}\text { Interaction effect I } \\
\text { (changes in mean area } \\
\text { and mean yield) }\end{array}$ & $\Delta \bar{A} \Delta \bar{Y}$ & $2 \Delta \bar{A} \Delta \bar{Y} C O V(A, Y)$ \\
\hline $\begin{array}{l}\text { Changes in area-yield } \\
\text { covariance }\end{array}$ & $\Delta C O V(A, Y)$ & $\{2 \bar{A} \bar{Y}-2 \operatorname{COV}(A, Y)\} \operatorname{COV}(A, Y)-\{\Delta C O V(A, Y)\}$ \\
\hline $\begin{array}{l}\text { Interaction effect II } \\
\text { (changes in mean area } \\
\text { and yield variance) }\end{array}$ & $\Delta \bar{A} \Delta V(Y)$ & $\left\{2 \bar{A} \Delta \bar{A}+(\Delta \bar{A})^{2}\right\} \Delta V(Y)$ \\
\hline $\begin{array}{l}\text { Interaction effect II } \\
\text { (changes in mean yield } \\
\text { and area variance) }\end{array}$ & $\Delta \bar{Y} \Delta V(A)$ & $\left\{2 \bar{Y} \Delta \bar{Y}+(\Delta \bar{Y})^{2}\right\} \Delta V(A)$ \\
\hline $\begin{array}{l}\text { Interaction effect IV } \\
\text { (changes in mean area } \\
\text { and mean yield and } \\
\text { changes in area-yield } \\
\text { covariance) }\end{array}$ & $\Delta \bar{A} \Delta \bar{Y} C O V(A, Y)$ & $(2 \bar{A} \Delta \bar{Y}+2 \bar{Y} \Delta \bar{A}+2 \Delta \bar{A} \Delta \bar{Y}) \Delta C O V(A, Y)$ \\
\hline \begin{tabular}{l} 
Residual \\
\hline
\end{tabular} & $\Delta R$ & $\Delta V(A Y)$ \\
\hline
\end{tabular}

\section{Change in variance decomposition}

The source of instability is caused by ten factors and shown below is the model:

$V(P)=\bar{A}^{2} \cdot V(Y)+\bar{Y}^{2} \cdot V(A)+2 \bar{A} \bar{Y} \operatorname{COV}(A, P)-\operatorname{COV}(A, Y)^{2}+R \cdot$

\section{Nerlovian model}

According to Sadiq et al. (2017), the basic model that has come to be called the Nerlovian model of price expectation is:

$A_{t}=\alpha+\beta_{i} P_{t}^{*}+\varepsilon_{t}$

$\left(P_{t}^{*}-P_{t-1}^{*}\right)=\beta\left(P_{t-1}-P_{t-1}^{*}\right) 0<\beta<1$..

Where;

$A_{t}=$ Actual acreage under the crop in year ' $t$ ' $P_{t}^{*}=$ Expected price of the crop in year ' $t$ '

$P_{t-1}^{*}=$ Expected price of the crop in year ' $t-1^{\prime}$

$P_{t-1}=$ Actual price of the crop in year' $t-1^{\prime}$

$\alpha=$ Intercept

$\beta=$ Coefficient of price expectation

$\varepsilon_{t}=$ Disturbance term

The Nerlovian model depicting farmer's behavior in its simplest form is shown below:

$A_{t}^{*}=\beta_{0}+\beta_{1} P_{t-1}+\beta_{2} P R_{t-1}+\beta_{3} Y_{t-1}+\beta_{t} \mathrm{CPR}_{t-1}+\beta_{5} T_{t}+\beta_{6} W_{t}+\varepsilon_{t}$ (21)
$A_{t}-A_{t-1}=B\left(A_{t}^{*}-A_{t-1}\right)($ Nerlovian adjustment equation $)$....(22)

As expected variables are not observable, for estimation purpose, reduced form containing only observable variables may be written after substituting the value of $A_{t}^{*}$ from equation (19) into equation (18), and is as follow:

$A_{i}^{i}=\beta_{0}+\beta_{1} P_{t-1}+\beta_{2} P R_{t-1}+\beta_{3} P_{t-1}+\beta_{4} P_{t-1}+\beta_{3} T_{t}+\beta_{6} W H_{t}+\beta_{7} A_{t-1}+\varepsilon_{t}$.

The first equation is a behavioural equation, stating that desired acreage $\left(A_{t}^{*}\right)$ depend upon the following independent variables:

Where,

$A_{t}=$ current area under the studied crop;

$P_{t-1}=$ one year lagged price of the studied crop;

$P R_{t-1}=$ one year lagged price risk of the studied crop;

$Y_{t-1}=$ one year lagged yield of the studied crop;

$Y R_{t-1}=$ one year lagged yield risk of the studied crop;

$T_{t}=$ time trend at period $t$;

$W I_{t}=$ one year lagged weather index;

$A_{t-1}=$ one year lagged area under the studied crop; 
$\beta_{0}=$ intercept

$\beta_{1-n}=$ parameter estimates ; and

$\varepsilon_{t}=$ Disturbance term.

Price and yield risks were measured using the standard deviation of the preceding three years. The weather impact on yield variability was measured by means of a Stalling index (Stalling, 1960) for the weather index. The yield was regressed on time to achieve the expected yield. The actual yield ratio to predicted is defined as the weather variable. In the acreage response model, the weather effects such as rainfall, temperature etc. may be captured by this index (Ayalew, 2015).

The extent to which the price and/or nonprice factors are adjusted is measured in terms of the "adjustment coefficient." The adjustment takes place in the previous year, in accordance with the actual area planted. If the adjustment coefficient is one, farmers themselves will adjust the area under the crop in the current year completely and there will be 'no lags' in the adjustment. But if the adjustment coefficient is less than one, the adjustment will continue and cause lags, which will be distributed over time. The number of years required to materialize 95 per cent of the price effect is given below (Sadiq et al. 2017):

$$
(1-r)^{n}=0.05
$$

Where;

$r=$ coefficient of adjustment (1-coefficient of lagged area); and,

$\mathrm{n}=$ number of year.

In the present study, both short-run (SRE) and long-run (LRE) elasticities of the area under the crop in terms of price were estimated to examine and compare the effect of price on the responsiveness of the area both in the short-run and long-run. Below are the price elasticities:

$S R E=$ Price coefficient $* \frac{\text { Mean of price }}{\text { Mean of area }}$.

$$
L R E=\frac{S R E}{\text { Coefficient of adjustment }}
$$

\section{ARIMA}

Box and Jenkins (1976) submitted that ARIMA $(p, d, q)$, which is a combination of Autoregressive (AR) and Moving Average (MA) with an integration or differentiation order (d), denotes a non-seasonal ARIMA model. The $p$ and q, respectively, are the autocorrelation order and the moving average (Gujarati et al. , 2012). The Auto-regressive of order $p$ denoted as AR $(p)$ is given below:

$Z_{t}=\alpha+\delta_{1} Z_{t-1}+\delta_{2} Z_{t-1}+\cdots . .+\delta_{p} Z_{t-p}+\varepsilon_{t} \ldots$

Where $\alpha$ is the constant; $\delta_{p}$ is the p-th autoregressive parameter and $\varepsilon_{t}$ is the error term at time't'.

The general Moving Average of (MA) of order $\mathrm{q}$ or MA (q) can be written as follow:

$Z_{t}=\alpha+\varepsilon_{t}-\varphi_{1} \varepsilon_{t-1}-\varphi_{2} \varepsilon_{t-1}-\cdots . .-\varphi_{q} \varepsilon_{t-q} \ldots$.

Where $\alpha$ is the constant; $\varphi_{q}$ is the q-th moving average parameter and $\varepsilon_{t-k}$ is the error term at time't-k'.

ARIMA in general form is as follows:

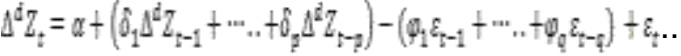

Where,

$\Delta$ denotes difference operator like:

$\Delta Z_{t}=Z_{t}-Z_{t-1}$

$\Delta^{2} Z_{t-1}=\Delta Z_{t}-\Delta Z_{t-1}$

Here, $Z_{t-1} \ldots \ldots, Z_{t-p}$ are values of past series with lag 1 p respectively.

Modeling using ARMA methodology consists of four steps viz. model identification, model estimation, diagnostic checking and forecasting.

\section{Forecasting Accuracy}

Mean absolute prediction error (MAPE), relative mean square prediction error (RMSPE), relative mean absolute prediction error (RMAPE) (Paul, 2014), Theil's $U$ statistics and $R^{2}$ were calculated using the following formulae for measuring the accuracy in fitted time series model:

$M A P E=1 / T \sum_{i=1}^{5}\left(A_{t-1}-F_{t-1}\right)$

RMPSE $=1 / T \sum_{i=1}^{5}\left(A_{t-1}-F_{t-1}\right)^{2} / A_{t-1}$

RMAPE $=1 / T \sum_{i=1}^{5}\left(A_{t-1}-F_{t-1}\right) / A_{t-1} \times 100 \ldots$ 


$$
\begin{aligned}
& U=\sqrt{\frac{\sum_{t=1}^{n-1} \frac{\left(P_{t+1}-Y_{t+1}\right)^{2}}{Y_{t}}}{\sum_{t=1}^{n-1} \frac{\left(Y_{t+1}-Y_{t}\right)^{2}}{Y_{t}}}} . \\
& R^{2}=1-\frac{\sum_{i=1}^{n}\left(A_{t i}-F_{t i}\right)}{\sum_{i=1}^{n}\left(A_{t i}\right)} .
\end{aligned}
$$

Where, $R^{2}=$ coefficient of multiple determination, $A_{t}=$ Actual value; $F_{t}=$ Future value, and $\mathrm{T}=$ time period

\section{RESULTS AND DISCUSSION Trend and growth patterns of rubber production}

The trend pattern of rubber production during the pre-SAP period was marked by a slight increase and decrease throughout the studied period with yield been the driving force for the rise as the change in the area remains stagnant over a long period of time (Figure 2). During the SAP period, the production trend was marked by a gentle rise during the early and late nineties with the incremental rise in the area been the driving force as successive changes in yield trend plummeted throughout the specified study period (Figure 3). Furthermore, during the postSAP period, a slight rise was only visible during the early twenties owing to slight incremental change in successive annual yield level as successive annual area was stagnant and thereafter the production trend from the midtwenties till the expiration period was marked by marginal rise due to small rise and fall in both the successive annual yield and area which interchange at different points in time (Figure 4). Therefore, it can be inferred that rubber production in the country was driven by incremental change in yield during the pre-SAP period while successive steep increase and a slight increase in the annual area were the driving forces behind rubber production during the SAP and post-SAP periods respectively. The explosive effect of yield during the pre-SAP period did not come as a surprise as the first national plan was export-oriented with a focus on cash crops as a source of raw material which was the driving force of western industrialization. Also, for the post-SAP period, it can be inferred that the sector was almost redundant as the successive annual production levels throughout the most part of the period remained stagnant owing to poor yield even with the slight rise in the area across the studied period.

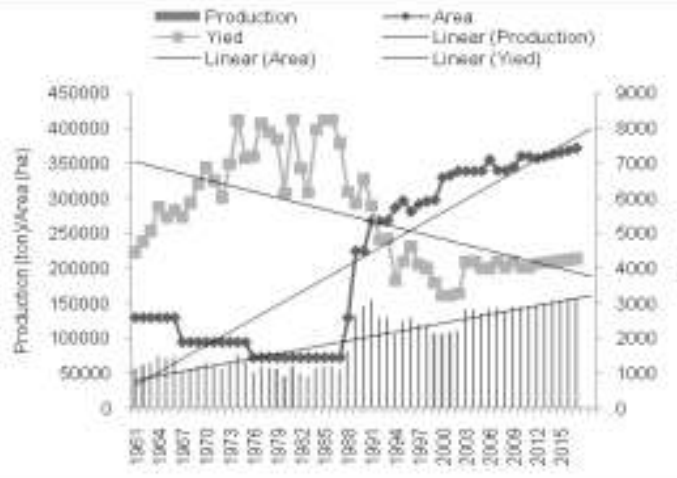

Figure 1. Production trend of rubber (1961-2017)

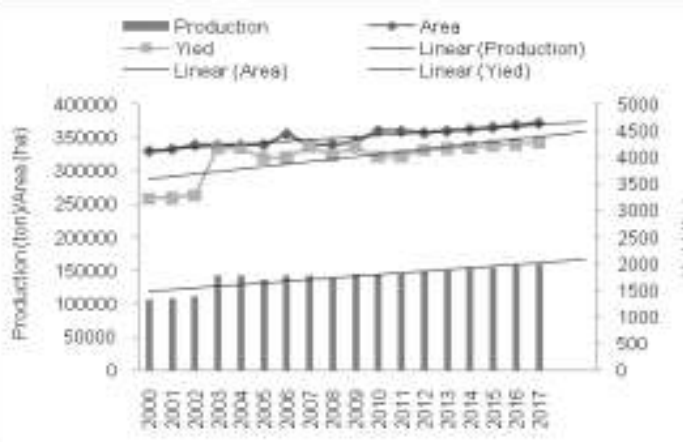

Figure 2. Pre-SAP production trend of rubber (1961-1984)

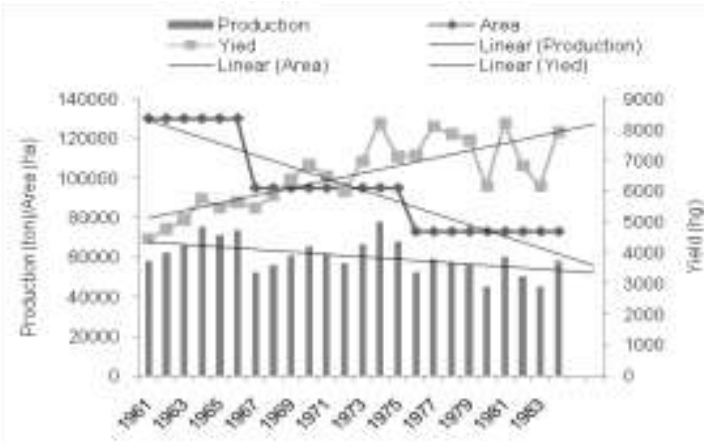

Figure 3. SAP production trend of rubber (1985-1999)

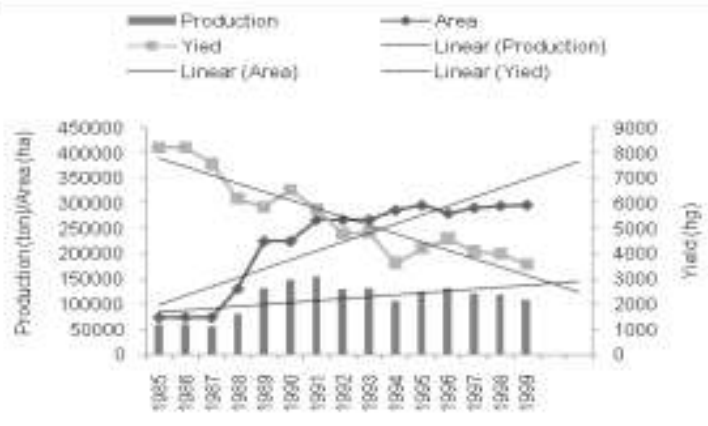

Figure 4. Post-SAP production trend of rubber (2000-2017) 
A cursory review of the results showed the average annual production of rubber to have increased by almost two-fold between pre-SAP and SAP periods and thereafter a small increase between the SAP and post-SAP period (Table $3)$. The explosive increase in area by almost three-fold was the major cause of the galloping rise in rubber production between pre-SAP and SAP regimes. Generally, the annual average area was on the increase across the regime shifts while the annual average yield was on the decrease across the regime shifts. Furthermore, a perusal of the growth pattern results showed the annual growth rate of rubber production to be on the trough during the pre-SAP period despite that yield recorded a positive annual growth rate. However, the negative annual growth rate which makes the production to trough owes to negative annual growth rate observed for area. During the SAP period, the annual production growth rate increased by $4.6 \%$ with an instantaneous $10.6 \%$ rise in the growth rate of area been the only driving force as yield was found to be on the trough due to the negative growth rate. For the post-SAP period, the rubber production witnessed a small incremental change in the growth rate by $1.9 \%$ with small incremental rise in the annual growth rates of both area and yield been the driving forces. Though, yield effect $(1.3 \%)$ was more pronounced in incremental growth which marked rubber production during the post-SAP era. However, for the overall period, the incremental rise in the annual growth rate of production was due to a positive annual growth rate in area as yield observed a negative growth rate. Therefore, it can be concluded that rubber production during the SAP period witnessed an impressive growth but it is not a healthy growth as an increase in the production level is due to an increase in area rather than technology i.e. yield (Table 3 ).

\section{Instability in rubber production and source of production risk}

A perusal of the Table showed production instability to be low and moderate during the pre-SAP and post-SAP; and SAP regimes respectively as evident by the $\mathrm{CV}$ indexes which were less than $20 \%$ for the former and higher than $20 \%$ but less than $40 \%$ for the latter (Table 4).While for the overall period, rubber production was marked by high instability as evident by the CV index which is greater than $40 \%$. However, the major reasons for low and moderate fluctuation in rubber production during the preSAP and SAP periods owed to low and moderate instability in the yield levels respectively. For high instability which marked the production for the overall period, high fluctuation in the area was observed to be the major cause. Therefore, it can be inferred that despite the poor production performance of rubber during the pre-SAP period, the extent of the production instability was low, thus exogenous factor may be the likely cause of negative production growth rate recorded during the stipulated study period.

Table 3. Growth pattern of rubber production

\begin{tabular}{|c|c|c|c|c|}
\hline Variables & Pre-SAP & SAP & Post-SAP & Overall \\
\hline Area (ha) & $95500(-3.1)^{\star \star \star}$ & $223566.7(10.6)^{\star \star \star}$ & $350347.9(0.7)^{\star \star \star}$ & $209680.1(3.2)^{\star \star \star}$ \\
\hline Yield (hg) & $6534.708(2.0)^{\star \star *}$ & $5484.2(-5.9)^{\star \star \star}$ & $3997.667(1.3)^{\star \star \star}$ & $5457.088(-1.1)^{\star \star \star}$ \\
\hline Production (ton) & $60560.38(-1.1)^{\star \star \star}$ & $110297.7(4.6)^{\star \star}$ & $140328.2(1.9)^{\star \star \star}$ & $98838.98(2.1)^{* \star *}$ \\
\hline
\end{tabular}

Source: Authors' computation, 2019

Note: Figure in parenthesis is CAGR

$* * * * * \star{ }^{N N S}$ means significant at $1,5,10 \%$ and Non-significant respectively.

Table 4. Extent of instability in rubber production

\begin{tabular}{|l|l|l|l|l|}
\hline Regimes & Variables & CV & CDII & CII \\
\hline Pre-SAP & Area & 0.236 & 8.509101 & 46.25296 \\
\hline & Yield & 0.171 & 10.51337 & 43.83258 \\
\hline SAP & Production & 0.144 & 12.31179 & 42.53909 \\
\hline & Area & 0.398 & 21.28463 & 64.3402 \\
\hline & Yield & 0.29 & 9.791527 & 48.79965 \\
\hline Post-SAP & Production & 0.29 & 23.07278 & 51.71077 \\
\hline & Area & 0.038 & 1.354208 & 38.21286 \\
\hline & Yield & 0.088 & 6.172559 & 40.42428 \\
\hline Overall & Production & 0.112 & 5.968665 & 41.53075 \\
\hline & Area & 0.569 & 32.88407 & 70.8594 \\
\hline & Yield & 0.282 & 21.66083 & 48.6214 \\
\hline
\end{tabular}


Table 5. Sources of instability in rubber production

\begin{tabular}{|l|l|l|l|}
\hline Source of variance & Pre-SAP to SAP & SAP to Post-SAP & Overall \\
\hline Change in mean yield & -177.30 & 2137.30 & 206.26 \\
\hline Change in mean area & 11.56 & -47.45 & 9.72 \\
\hline Change in yield variance & 80.54 & 659.44 & 137.05 \\
\hline Change in area variance & 1547.00 & 1098.46 & 1405.53 \\
\hline Interaction between changes in mean yield and mean area & 30.49 & -247.35 & -45.75 \\
\hline Change in area yield covariance & -775.96 & -1671.72 & -749.69 \\
\hline Interaction between changes in mean area and yield variance & 360.86 & 959.98 & 104.48 \\
\hline Interaction between changes in mean yield and area variance & -457.41 & -514.79 & -1332.79 \\
\hline $\begin{array}{l}\text { Interaction between changes in mean area and yield and change } \\
\text { in area-yield covariance }\end{array}$ & -687.37 & -229.01 & 1042.51 \\
\hline Change in residual & 167.57 & -2044.86 & -677.33 \\
\hline Total change in variance of production & 100 & 100 & 100 \\
\hline
\end{tabular}

Source: Authors' computation, 2019

Table 6. Sources of change in rubber production (Intra-wise \%)

\begin{tabular}{|l|l|l|l|l|}
\hline Source of change & Pre-SAP & SAP & Post-SAP & Overall \\
\hline Area effect & 0 & 305.4656 & 31.84607 & 134.7209 \\
\hline Yield effect & 0 & -168.753 & 69.06265 & -16.5962 \\
\hline Interaction effect & 0 & -36.6874 & -0.8735 & -18.1263 \\
\hline Total change & 100 & 100 & 100 & 100 \\
\hline
\end{tabular}

Source: Authors' computation, 2019

Table 7. Sources of change in rubber production (Inter-regime wise \%)

\begin{tabular}{|l|l|l|}
\hline Source of change & Pre-SAP to SAP & SAP to Post-SAP \\
\hline Area effect & -19.20 & -123.18 \\
\hline Yield effect & 160.17 & 257.71 \\
\hline Interaction effect & -25.75 & -69.85 \\
\hline Co-variance effect & -15.22 & 35.33 \\
\hline Total change & 100 & 100 \\
\hline
\end{tabular}

Source: Authors' computation, 2019

Table 8. Farmers' acreage response

\begin{tabular}{|l|l|l|l|l|l|}
\hline Variables & Parameters & t-stat & Mean & SRE & LRE \\
\hline Intercept & $34928.9(34928.9)$ & $2.150^{\star *}$ & - & - & - \\
\hline $\mathrm{P}_{\mathrm{t}-1}$ & $-0.2468(0.1355)$ & $1.821^{*}$ & 41865.26 & -0.04754 & -0.17607 \\
\hline $\mathrm{PR}_{\mathrm{t}-1}$ & $0.066(0.3195)$ & $0.206^{\mathrm{NS}}$ & 5667.686 & 0.001721 & 0.006374 \\
\hline $\mathrm{Y}_{\mathrm{t}-1}$ & $-1.85(4.39326)$ & $0.421^{\mathrm{NS}}$ & 5387.075 & -0.04585 & -0.16983 \\
\hline $\mathrm{YR}_{\mathrm{t}-1}$ & $1.662(9.364)$ & $0.177^{\mathrm{NS}}$ & 419.4214 & 0.003207 & 0.011879 \\
\hline $\mathrm{T}_{\mathrm{t}}$ & $2449.38(577.17)$ & $4.244^{* * *}$ & 26 & 0.293013 & 1.085233 \\
\hline $\mathrm{Wl}_{\mathrm{t}}$ & $-57703.4(22012.0)$ & $2.621^{* *}$ & 1.003672 & -0.26647 & -0.98693 \\
\hline $\mathrm{A}_{\mathrm{t}-1}$ & $0.73(0.0953)$ & $7.655^{\star * *}$ & 213240.8 & 0.716226 & 2.65269 \\
\hline $\mathrm{R}^{2}$ & 0.9843 & & & & \\
\hline F-stat & $385.95\{1.17 \mathrm{e}-36\}^{\star * *}$ & & & & \\
\hline Autocorrelation & $1.961\{0.119\}^{\mathrm{NS}}$ & & & & \\
\hline Arch effect & $0.0466\{0.828\}^{\mathrm{NS}}$ & & & & \\
\hline Heteroscedasticity & $7.932\{0.338\}^{\mathrm{NS}}$ & & & & \\
\hline Normality & $21.11\{2.6 \mathrm{e}-5\}^{* * *}$ & & & & \\
\hline CUSUM test & $1.502\{0.140\}^{\mathrm{NS}}$ & & & & \\
\hline RESET test & $5.2778\{0.8208\}^{\mathrm{NS}}$ & & & & \\
\hline
\end{tabular}

Source: Authors' computation, 2019, Note: ${ }^{* * * * * N 5}$ means significant at $1 \%, 5 \%, 10 \%$ probabilities and Non-significant respectively.

Values in ( ), [ ] and \{ $\}$ are standard error, t-statistic and probability level respectively.

Table 9. ARIMA model

\begin{tabular}{|c|c|c|c|c|}
\hline \multicolumn{2}{|c|}{ ARIMA } & Production (AIC) & Area (AIC) & Yield (AIC) \\
\hline \multicolumn{2}{|c|}{ ARIMA $(1,1,1)$} & 1220.82 & 1258.15 & 894.406 \\
\hline \multicolumn{2}{|c|}{ ARIMA $(1,1,0)$} & 1218.84 & 1257.05 & 894.299 \\
\hline \multicolumn{2}{|c|}{$\operatorname{ARIMA}(0,1,1)$} & 1218.82 & 1257.69 & 892.839 \\
\hline \multicolumn{2}{|c|}{ Autocorrelation } & $2.959(0.3960)^{\mathrm{NS}}$ & $2.1319(0.545)^{\mathrm{NS}}$ & $2.922(0.495)^{\mathrm{NS}}$ \\
\hline \multicolumn{2}{|c|}{ Arch effect } & $2.488(0.477)^{\mathrm{NS}}$ & $8.0259(0.1548)^{\mathrm{NS}}$ & $14.786(0.1400)^{\mathrm{NS}}$ \\
\hline \multicolumn{2}{|c|}{ Normality } & $16.454(0.00026)^{\star * \star}$ & $28.888(5.33 \mathrm{e}-07)^{\star \star \star}$ & $2.427(0.297)^{\mathrm{NS}}$ \\
\hline \multirow[t]{2}{*}{ ADF } & Level & $-0.889(0.7846)^{\mathrm{NS}}$ & $-0.237(0.9313)^{\mathrm{NS}}$ & $-0.9223(0.7818)^{\mathrm{NS}}$ \\
\hline & $1^{\text {st }}$ Diff. & $-6.542(6.08 e-7)^{\star \star \star}$ & $-5.674(1.19 e-05)^{\star * \star}$ & $-7.340(3.86 \mathrm{e}-011)^{\star \star \star}$ \\
\hline
\end{tabular}

Source: Authors' computation, 2019, Note: ${ }^{* \star \star N S}$ means significant at $1 \%$ probability and Non-significant respectively.

Values in ( ), [ ] and \{\} are standard error, $t$-statistic and probability level respectively. 
Table 10. One-step ahead forecast of rubber production

\begin{tabular}{|l|l|l|l|l|l|l|}
\hline Period & Production & Area & Yield \\
\cline { 2 - 7 } & Actual & Forecast & Actual & Forecast & Actual & Forecast \\
\hline 2013 & 150110 & 150020.4 & 359859 & 359978.6 & 4171 & 4103.45 \\
\hline 2014 & 152298 & 151932.6 & 362658 & 363721.1 & 4199 & 4145.14 \\
\hline 2015 & 154571 & 154149.7 & 365622 & 366586.7 & 4228 & 4177.18 \\
\hline 2016 & 156900 & 156428.6 & 368676 & 369590.4 & 4256 & 4207.08 \\
\hline 2017 & 159264 & 158762.9 & 371775 & 372666.1 & 4284 & 4235.64 \\
\hline
\end{tabular}

Source: Authors' computation, 2019

Table 11. Validation of models

\begin{tabular}{|l|l|l|l|l|l|l|}
\hline Variable & $\mathbf{R}^{2}$ & RMSE & RMSPE & MAPE & RMAPE (\%) & Theil's U \\
\hline Production & 0.997725 & 396.0568 & 1.003552 & 351.834 & 0.225509 & 0.193138 \\
\hline Area & 0.997904 & 859.1978 & 2.013157 & -766.67 & -0.20894 & 0.322523 \\
\hline Yield & 0.990446 & 45.2005 & 0.481984 & 40.392 & 0.952592 & 1.789165 \\
\hline
\end{tabular}

Source: Authors' computation, 2019

Table 12. Out of sample forecast of the variables

\begin{tabular}{|c|c|c|c|c|c|c|}
\hline \multirow[t]{2}{*}{ Year } & \multicolumn{3}{|l|}{ Production } & \multicolumn{3}{|l|}{ Area } \\
\hline & Forecast & LCL & UCL & Forecast & LCL & UCL \\
\hline 2018 & 161130.03 & 137205.30 & 185054.76 & 375775.92 & 342132.33 & 409419.52 \\
\hline 2019 & 162943.19 & 127278.74 & 198607.63 & 379993.87 & 326383.81 & 433603.92 \\
\hline 2020 & 164756.34 & 120354.62 & 209158.07 & 384264.04 & 315107.77 & 453420.30 \\
\hline 2021 & 166569.50 & 114887.07 & 218251.93 & 388546.77 & 306496.08 & 470597.45 \\
\hline 2022 & 168382.65 & 110325.49 & 226439.81 & 392832.52 & 299601.56 & 486063.49 \\
\hline 2023 & 170195.81 & 106397.73 & 233993.88 & 397119.01 & 293900.24 & 500337.78 \\
\hline 2024 & 172008.96 & 102945.55 & 241072.37 & 401405.67 & 289081.16 & 513730.18 \\
\hline 2025 & 173822.12 & 99867.30 & 247776.93 & 405692.37 & 284946.29 & 526438.44 \\
\hline 2026 & 175635.27 & 97093.09 & 254177.46 & 409979.08 & 281361.55 & 538596.60 \\
\hline 2027 & 177448.43 & 94572.40 & 260324.45 & 414265.79 & 278231.50 & 550300.09 \\
\hline 2028 & 179261.58 & 92267.36 & 266255.81 & 418552.51 & 275485.42 & 561619.60 \\
\hline 2029 & 181074.74 & 90148.64 & 272000.84 & 422839.22 & 273069.21 & 572609.23 \\
\hline \multirow[t]{2}{*}{ Year } & \multicolumn{3}{|l|}{ Yield } & & & \\
\hline & Forecast & $\overline{L C L}$ & UCL & & & \\
\hline 2018 & 4263.80 & 2962.16 & 5565.45 & & & \\
\hline 2019 & 4257.87 & 2665.23 & 5850.50 & & & \\
\hline 2020 & 4251.93 & 2413.80 & 6090.06 & & & \\
\hline 2021 & 4246.00 & 2191.50 & 6300.49 & & & \\
\hline 2022 & 4240.06 & 1989.92 & 6490.21 & & & \\
\hline 2023 & 4234.13 & 1804.03 & 6664.23 & & & \\
\hline 2024 & 4228.19 & 1630.58 & 6825.81 & & & \\
\hline 2025 & 4222.26 & 1467.30 & 6977.22 & & & \\
\hline 2026 & 4216.32 & 1312.53 & 7120.12 & & & \\
\hline 2027 & 4210.39 & 1165.02 & 7255.76 & & & \\
\hline 2028 & 4204.46 & 1023.81 & 7385.10 & & & \\
\hline 2029 & 4198.52 & 888.13 & 7508.91 & & & \\
\hline
\end{tabular}

Source: Authors' computation, 2019

Furthermore, a review of the exact direction of the production instability showed a similar trend with what was obtained when CV was applied except that the production instability for the overall period turn-out to be moderate as indicated by the CDII index which was between 20 to $39 \%$. Therefore, it can be inferred that rubber production across the policy regime periods in the country was within the comfort zone from the exact directional point of view (Table 4). The results of the CII index showed high fluctuation in rubber production across the policy regime periods as evident by the CII indexes which were higher than $40 \%$. Evidence showed all the production parameters viz. area and yield to be marked by explosive fluctuation across all the policy periods under investigation.

Therefore, from the point of production instability in relation to price trend, it can be inferred that rubber production in the country was not in the comfort zone across the policy regime periods (Table 4).

Furthermore, a critical investigation of the source of instability across regime shifts showed 'change in area variance' to be the major source of fluctuation in rubber production between pre- 
SAP and SAP periods; while between SAP and post-SAP regimes, 'change in the average yield' was the major cause of production instability. However, for the overall period i.e. across the policy regime shifts, 'interaction between change in average area and yield' featured as the major cause of instability in rubber production in the country (Table 5). Therefore, it can be inferred that the major cause of rubber production instability centered majorly on risk.

\section{Source of change in rubber production}

The results of the instantaneous source of increase in the average annual production level of rubber across the policy regimes independently showed area effect to be the major source of incremental change in the average annual output level during the SAP and the overall periods; while technology effect was observed to be the production incremental driving force during the post-SAP period. However, the average annual rubber output level was dormant during the pre-SAP period as evident by the parameter estimates which were zero (Table 6). Furthermore, for the inter-regime wise, evidence showed area effect to be the source of the incremental rise in the output level of rubber between the pre-SAP and SAP, and SAP and post-SAP. This clearly indicates that technology was the driving force behind the increase in rubber production in the country when the sub-sector was undergoing a paradigm shift (Table 7).

\section{Farmers' acreage response}

The results of the Autoregressive distributed lag model showed the linear functional form to be the best fit for the specified equation as the classical linear regression model satisfied the economic, statistical and econometric criteria, thus selected as the best fit (Table 8). The autoregression test at lag four (4) showed that the residuals were independent as indicated by the Langrage Multiplier (LM) test, which at 10 per cent degree of freedom was not different from zero, so no serial correlation. The heteroscedasticity test using the robust variant test showed the variance of the residual being constant as indicated by the LM test statistics, which at 10 percent degree of freedom is not different from zero, thus implying that the residual square sum is homoscedastic. This clearly showed that for prediction the leastsquares are efficient and reliable. There is no evidence of a correlation between the residual variance as indicated by the LM test statistics that is not different from zero at 10 percent degree of freedom, implying that the residual does not have an Arch effect. Furthermore, the results of the diagnostic test showed that the parameter estimates were stable and that the functional form specification is adequate as indicated by the CUSUM and RESET test statistics respectively, which were not different from zero at 10 percent degree of freedom, thus implying no change in parameters and adequate model specification. However, the residual was found not to be normally skewed as indicated by the $\mathrm{Chi}^{2}$ test statistics, which at 10 percent degree of freedom differ from zero. Though, literature has shown that non-normality in the distribution of residual is not considered a serious challenge as data in their natural forms are likely not to be normally distributed. Therefore, with the above ample evidence, it can be inferred that the least-squares are efficient and reliable to predict farmers' acreage response with high precision and certainty.

The value of the multiple determination coefficient being 0.984 implies that 98.4 percent of the current cultivated acreage is determined by the explanatory variables captured in the model while the perturbed economic reality represents the percentage left-over. The high value of the $R^{2}$ will create a suspicious of spurious correlation but with the absence of a serial correlation as indicated by the LM test, it can be affirmed that the variables did not move together with the time trend, thus the model is devoid of spurious correlation and is not a nonsense regression. Thus, the model is reliable for long-run prediction.

Furthermore, the variables found to have an impact on the current rubber acreage cultivated are weather vagaries, producer price, time factor and the lagged area under rubber cultivation as evident by their respective parameter estimates which were different from zero at $10 \%$ degree of freedom. The negative significant of the Weather Index (WI) implies that the current acreage under rubber production decrease owing to weather vagaries which are caused by climate change. The decline in the productivity of rubber has dire consequences on the turn-over of the enterprise as it has the tendency of forcing the farmers to diversify to other cash crops, thus affecting the hectare cultivated for rubber in the country. The consequence of climate change due to indiscriminate human exploitation of the environmental resources caused dry-spell and flood with dare consequences on the production of rubber in the country. 
The negative significant of the producer price showed how dampening of the price due to glut in the supply which in turn affected the business turn-over led to a decrease in the current acreage cultivated for rubber. This did not come as a surprise as the farmers have no direct link with the importing market and have to rely on the licensed buyers (LBs) who engaged in the exportation of the commodity. The LBs take advantage of lack of market tie-up between the producers and importers to exploit the farmers with respect to the price to their advantage. This exploitation tendency of the middlemen i.e. LBs is what is killing the cash crop sub-sector in Africa as most of the farmers leased-in the plantations, thus living them with very marginal turn-over which can hardly sustain their family expenditure more or less the going concern of the business. Moreover, the negative relationship has a connection with the nonavailability of remunerative substitute crops for cultivation, since substitute crops require extra capital for cultivation, well-known that capital is the major constraint affecting farmers; they tend to stick to this crop. So they produce the crop regardless of the prevailing market price.

The SRE and LRE showed rubber farmers' acreage responsiveness to price changes in the previous crop period and the elasticities were respectively 0.05 and 0.18 percent. Since the LRE reflects the acreage responsiveness of rubber crops to a price change if sufficient time is given for adjustment, the long-run impact of price policy on rubber production is therefore small due to the low LRE value. Furthermore, it will take approximately 2.29 years for the price effect to materialize. Since the time required for adjustment of the price effect is small, it can be inferred that the price policy instrument will be effective in bringing about the desired change in rubber production supply.

The positive significant of the time trend implies that the different policy regimes witnessed by the economy impacted positively on rubber production in the country, thus encouraged an increase in the current acreage cultivated under rubber. The establishment of rubber research institutes to develop technologies aimed at increasing rubber production, establishment of agencies with the mandate of export promotion both at state and national level, bilateral and multilateral agreement in trade organization both at regional, continental and international (WTO) levels, foreign investment in the sub-sector, protection policies viz. embargo, tariff, export promotion etc are all visible policies aimed at reviving the subsector in the country. Furthermore, empirical evidence showed that the rate of adjustment of area under rubber was low as evident by the calculated adjustment coefficient value of 0.27 . Thus, the adjustment in accordance with the actual area planted in the preceding year will continue and will result in lags which will be distributed over time. The positive significant of the efficiency parameter indicated that technology impacted positively on the current acreage under rubber production in the country.

\section{Production forecast of rubber in Nigeria}

Results of the unit root test showed that variables residuals viz. area, yield and level production were pure white noise but after differentiation (first difference) the residuals became Gaussian white noise as evident by their respective ADF test statistics which were not different from zero and differed from zero at an error gap of 5 percent, respectively (Table 9). This implies that the variables after differencing became stationary which is a prerequisite for the efficiency of time series data. Thereafter, for forecasting, the variables were subjected to various ARIMA stages to determine the most suitable ARIMA model with the lowest Akaike information criterion (AIC). The empirical evidence showed that for the area, yield and output; ARIMA $(1,1,0)$, ARIMA $(0,1,1)$ and ARIMA $(0,1,1)$, respectively, were selected as the best fit for the forecast because they had the lowest AICs among all the ARIMA forms tested (Table 9). Furthermore, the residuals of the selected ARIMAs were devoid of autocorrelation, arch effect and are normally distributed as indicated by their respective test statistics, which at 10 percent error gap were no different from zero. However, the residual of the selected ARIMA for the production variable was found not to be normally skewed as it is different from zero at $10 \%$ degree of freedom. However, literature has shown that non-normality in the distribution of the term of error is not a serious problem since in most cases data are not normally distributed in their natural form.

In determining the predictive power of the selected ARIMAs, one-step-ahead forecast of the variables and their corresponding standard errors were calculated using the naïve approach for the periods 2013 to 2017 (Table 10). This was done to validate how closely the sample periods could track the path of actual observation. 
The mean absolute prediction error (MAPE), root mean square error (RMSE), Theil's inequality coefficient $(U)$, and the relative mean absolute prediction error (RMAPE) have been determined in measuring the reliability of the selected ARIMAs for the forecast. Empirical evidence showed that the RMAPE and $U$ coefficients were below 5 percent and 1 respectively, indicating that the predictive error associated with the estimated equations was very low and insignificant in tracking the actual data (ex-post prediction) and thus could be used for ex-ante projection with high projection validity, efficiency and consistency (Table 11).

Table 12 and Figure 6-8 showed the estimated one-step-ahead out of sample forecasts of rubber production (ton), area (hectare) and yield (hg) spanning through 2018 to 2029. It was observed that the production will be marked by a gentle rise throughout the forecasted period owing to a gentle rise in the area. It is saddened to observe that the yield will be marked by a gentle fall throughout the forecasted period as evidenced by the plummeting forecasted yield trend. Therefore, the study calls for urgent intervention by both government and non-governmental agencies in linking the producers with the importing market in order to have a better price for their products. In addition, the farmers should form viable cooperative organizations that will be directly involved in marketing, especially exportation in order to have strong bargaining power for their products, thus fetching them remunerative prices that will make their income productive.

\section{CONCLUSION}

From the findings, it can be inferred that the incremental changes in rubber production between the policy regime shifts in the country are been driven by area effect which does not signify healthy growth in the rubber sub-sector of the country. Furthermore, area risk due to competing demand for limited available land seriously affected the production of rubber in Nigeria. The future of the rubber sub-sector is not impressive as the gentle rise in the forecasted production trend will be driven by area increase as the future annual yield levels plummeted. Price dampening due to lack of market-tie of the producers with the importing markets which makes the farmers to be at the mercy of the LBs will affect farmers' income productivity, thus affecting their livelihoods and the enterprise business going concern. Therefore, for a healthy market competition, the farmers should constitute themselves into viable co-operative associations in order to be competitive enough to venture into direct marketing i.e. exportation of their products and the government and non-government agencies should assist in linking these farmers' cooperatives directly with the importing markets. By so doing, the farmers will have bargaining power for their products, thus making them to earn productive income owing to remunerative prices from their products.

\section{AUTHOR'S CONTRIBUTION}

M. S. Sadiq: $40 \%$

I. P. Singh: $30 \%$

M. Ahmad: $30 \%$

\section{REFERENCES}

Agbota, S. 2017. Nigeria's rubber plantation going extinct. The Sun Newspaper. https://www.sunnewsonline.com/nigeriasrubber-plantation-going-extinct.

Ahmed, S. I. and M. B. Joshi. 2013. Analysis of instability and growth rate of cotton in three districts of Marathwada. International Journal of Statistika and Mathematika, 6 (3): 121-124.

Ambrose, N. 2018. How to rejuvenate rubber Industry. The Nation Newspaper. https:// thenationonlineng.net/how-to-rejuvenate-rubberindustry.

Ayalew, B. 2015. Supply response of maize in Ethiopia: Cointegeration and Vector Error Correction Approach. Trends in Agricultural Economics, 8 (1): 13-20.

Boyal, V. K., D. C. Pant and J. Mehra. 2015. Growth, instability and acreage response function in production of cumin in Rajasthan. The Bioscan, 10 (1): 359-362.

Central Intelligence Agency. 2011. The World Factbook. Central Intelligence Agency.

Coppock, J .D. 1962. International Economic Instability. McGraw-Hill, New York, pp. 523525.

Cuddy, J. D. A. and P. A. D. Valle. 1978. Measuring the instability of time series data. Oxford Bulletin and Economic Statistics, 40: 53-78.

Gujarati, D., D. Porter and S. Gunasekar. 2012. Basic Econometrics. McGraw Hill, New Delhi.

Hazell, P. B. R. 1982. Instability in Indian food grain production. Research Report, 30, Washington, D.C., USA: International Food Policy Research Institute. 
Kumar, N. S., B. Joseph and J. P. K. Muhammed. 2017. Growth and Instability in area, production, and productivity of cassava (Manihot esculenta) in Kerala. International Journal of Advance Research, Ideas and Innovations in Technology, 4 (1): 446-448.

Legume Breeders Workshop, IITA Ibadan, Nigeria.

Paul, R. K. 2014. Forecasting whole sale price of pigeon pea using long memory timeseries models. Agricultural Economics Research Review, 27 (2): 167-176.

Sadiq, M. S., I. P. Singh and N. Karunakaran. 2017. Supply response of cereal crop farmers to price and non-price factors in Rajasthan state of Nigeria. Journal of Agricultural Economics and Rural Development, 3 (2): 203-210.

Sandeep, M. V., S. S. Thakare and D. H. Ulemale. 2016. Decomposition analysis and acreage response of pigeon-pea in western Vidarbha. Indian Journal of Agricultural Research, 50 (5): 461-465.

Sinmar, R. 2014. Growth and instability in agricultural production in Haryana: A district level analysis. International Journal of Scientific and Research Publications, 4 (7): 1-12.

Stalling, J. L. 1960. Weather indexes. Journal of Farm Economics, 42: 180-186.

Umar, S. M., K. Suhasini, S. M. Jainuddin and S. A. Makama. 2019. Sources of growth and instability in cassava production in Nigeria: An evidence from Hazell's Decomposition Model. SKUAST Journal of Research, 21 (1): 86-95.

Umar, S. M., K. Suhasini, M. S. Sadiq and A. Aminu. 2017. Growth and Instability in yam production in Nigeria: An Inter Zone and State Level Analysis. Dutse Journal of Agriculture and Food Security, 4 (1): 10-24.

(Received: May 03, 2019; Accepted: June 24, 2020) 